\section{Important Marine Mammal Areas: a spatial tool for marine mammal conservation}

The Marine Mammal Protected Areas Task Force of the IUCN Species Survival Commission and World Commission on Protected Areas announces the completion of entries for 159 Important Marine Mammal Areas (IMMAs), available at marinemammalhabitat.org. This tool highlights areas that are important for one or more marine mammal species and that have the potential to be managed for conservation. These areas are not marine protected areas: they are biocentric with no legal, political or socio-economic basis. The IMMA tool is already being used to create or modify marine protected areas and to address ship-strike and noise issues for whales.

Important Marine Mammal Areas are modelled on Important Bird and Biodiversity Areas (birdlife.org/worldwide/programme-additional-info/important-bird-and-biodiversity-areas-ibas) but with criteria supporting the 130 marine mammal species, including whales, dolphins, porpoises, seals and sea lions, sea otters, manatees, dugongs and polar bears. These megafauna serve as indicators of the biodiversity and health of the oceans.

The Task Force holds intensive week-long workshops with 20-40 scientists per region, who contribute their expertise to define candidate IMMAs. These candidate IMMAs are then presented to an independent review panel, which typically approves $70-80 \%$ of the candidate sites as full IMMAs. Candidate IMMA proposals without sufficient evidence supporting one or more IMMA criteria (marinemammalhabitat. org/immas/imma-criteria) acquire the lesser status of Areas of Interest, and others remain as candidate IMMAs if close to approval.

After the first workshop in the Mediterranean in 2016, the Task Force conducted workshops and reviews in five southern hemisphere regions comprising one-third of the global ocean. In 2020 there was a sixth workshop covering Australia, New Zealand and the South-east Indian Ocean, in which 31 new IMMAs passed peer review, many of them identifying habitats for endemic or threatened species.

As of 2021, the Task Force has received $>180$ requests for IMMA shapefiles and metadata. The Task Force has gained recognition from the UN Convention on Migratory Species and the Convention on Biological Diversity, and held discussions with the International Maritime Organization, to use IMMAs in conservation planning.

The IMMA work has been largely sponsored by the German International Climate Initiative through the Global Ocean Biodiversity Initiative, the French Biodiversity Agency through the IUCN Global and Polar Marine Programme, and the MAVA Foundation, administered through Tethys Research Institute in Italy and Whale and Dolphin Conservation in the UK.
In 2021, the Task Force will conduct workshops covering the Black and Caspian Seas, followed by the Eastern Temperate and Tropical Pacific (Mexico to Chile).

ERICH HOYT (๑ orcid.org/0000-0001-6946-4055) IUCN Marine Mammal Protected Areas Task Force, and Whale and Dolphin Conservation, Chippenham, UK E-mailerich.hoyt@whales.org

Giuseppe Notarbartolo di SCIARA (○ orcid.org/0000-00030353-617X) IUCN Marine Mammal Protected Areas Task Force, and Tethys Research Institute, Milan, Italy

This is an Open Access article, distributed under the terms of the Creative Commons Attribution licence CC BY 4.0

\section{Artificial nest cavities can sustain populations of hornbills in the degraded forests of Kinabatangan, Borneo}

Eight hornbill species occur in the Kinabatangan floodplain, a biodiversity hotspot in eastern Sabah, Malaysian Borneo. Through regular monitoring, Hutan, a community-based conservation NGO working in Kinabatangan since 1998, has detected a steady decline of hornbills in this area. We have determined that neither poaching nor lack of food is the primary cause of decline. Hornbills are cavity-nesting birds; the female and the chicks spend several months sealed in natural tree holes until fledging. Previous heavy timber extraction in Kinabatangan destroyed cavities suitable for nesting, and pioneer trees now colonize the regenerating forests. Tree cavities formed in these fast-growing trees have relatively short life spans, deteriorating as a result of heart rot. Their entrance closes rapidly, they are too small for large birds such as the Critically Endangered helmeted hornbill Rhinoplax vigil or the Vulnerable rhinoceros hornbill Buceros rhinoceros, and there is intense competition with other cavity users. The loss of suitable nest cavities directly threatens the long-term survival of hornbills in Kinabatangan.

In 2013, Hutan and several zoo partners (Beauval, Chester, Phoenix, Nashville, Woodland Park and Houston) built artificial nests for hornbills using plastic barrels. Hornbills soon visited the nest boxes, but as far as we are aware it was 3 years before one was first used, by a pair of rhinoceros hornbills. During 2017-2019, two rhinoceros hornbill pairs used these plastic nest boxes and produced five living chicks. The growth of lichen on the nest box surface not only created a more natural appearance but may have been instrumental in the absorption of light energy, reducing the temperature within the nest cavity. In total, we have installed 25 nest boxes using various models and materials (wood, fiberglass, plastic). Wooden boxes have attracted several pairs of Endangered wrinkled hornbills Aceros corrugatus, and bushycrested Anorrhinus galeritus and oriental pied hornbills 